\title{
Home mechanical ventilation in Australia and New Zealand
}

\author{
Daniel J. Garner, David J. Berlowitz, James Douglas, Nick Harkness, \\ Mark Howard, Nigel McArdle, Matthew T. Naughton, Alister Neill, \\ Amanda Piper, Aeneas Yeo and Alan Young
}

ABSTRACT: This study aims to describe the pattern of home mechanical ventilation (HMV) usage in Australia and New Zealand.

34 centres providing HMV in the region were identified and asked to complete a questionnaire regarding centre demographics, patient diagnoses, HMV equipment and settings, staffing levels and methods employed to implement and follow-up therapy.

$28(82 \%)$ centres responded, providing data on 2,725 patients. The minimum prevalence of HMV usage was 9.9 patients per 100,000 population in Australia and 12.0 patients per 100,000 population in New Zealand. Variation existed across Australian states (range 4-13 patients per 100,000 population) correlating with population density $(r=0.82 ; p<0.05)$. The commonest indications for treatment were obesity hypoventilation syndrome (OHS) (31\%) and neuromuscular disease (NMD) (30\%). OHS was more likely to be treated in New Zealand, in smaller, newer centres, whilst NMD was more likely to be treated in Australia, in larger, older centres. Chronic obstructive pulmonary disease was an uncommon indication $(\mathbf{8 . 0} \%)$. No consensus on indications for commencing treatment was found.

In conclusion, the prevalence of HMV usage varies across Australia and New Zealand according to centre location, size and experience. These findings can assist HMV service planning locally and highlight trends in usage that may be relevant in other countries.

KEYWORDS: Chronic obstructive pulmonary disease, chronic respiratory failure, home mechanical ventilation, neuromuscular disorders, noninvasive ventilation, obesity hypoventilation syndrome

$\mathrm{H}$ ome mechanical ventilation (HMV) is an established treatment for chronic ventilatory failure [1-3]. HMV improves survival and quality of life for selected patients with neuromuscular disease (NMD) [4-6] and kyphoscoliosis $[7,8]$ and improves blood gas abnormalities and quality of life for obesity hypoventilation syndrome (OHS) [9-11] and cystic fibrosis $[12,13]$. However, the role in chronic obstructive pulmonary disease (COPD) remains controversial [14-16], with a recent Australian randomised controlled trial demonstrating improved survival but decreased quality of life [17], and others using a high-intensity approach finding treatment to be more effective and well tolerated [18].

A survey of HMV centres in Europe revealed wide variation in the prevalence and pattern of HMV prescription [19]. The prevalence rate for HMV usage was highest in countries that had longstanding HMV services [19]. There was considerable variation in the proportion of patients treated for lung disease or NMD when compared with other countries [19]. Data on HMV usage are scarce around the world, with comparable data available only in Hong Kong, Norway and Sweden [20-22]. Previous small studies have examined the situation in Australia [23], and shown that the treatment is well tolerated by local populations [24]; however, no recent or comprehensive data are available for the region as a whole.

The aim of this study was to describe the prevalence and pattern of HMV usage in Australia and New Zealand, focusing on the treating centres, indications for treatment, machine settings, and methods of implementation and follow-up. The study hypothesis was that the prevalence and pattern of HMV usage would vary according to centre location, size and experience.
AFFILIATIONS

For author affiliations, please see the Acknowledgements section.

CORRESPONDENCE

D.J. Garner

Allergy, Immunology and Respiratory Medicine

$5^{\text {th }}$ Floor

Main Ward Block

The Alfred Hospital

55 Commercial Road

Prahran

Melbourne

Victoria 3181

Australia

E-mail: daniel garner@hotmail.com

Received:

Nov 242011

Accepted after revision:

March 212012

First published online:

May 312012 


\section{MATERIALS AND METHODS}

Ethical approval was granted by the Human Research Ethics Committee at The Alfred Hospital, Melbourne, Australia, which acted as the primary centre for coordinating data collection and analysis.

For the purposes of the study, HMV was defined as bi-level positive pressure or volume-cycled ventilation delivered via a facemask or tracheostomy, negative pressure ventilation, or phrenic nerve stimulation, delivered at home or in a chronic care environment for $>3$ months.

\section{Centre identification}

A group of experienced HMV clinicians from the Australasian Sleep Association identified eligible centres, defined as those that had prescribed HMV for $>3$ months to more than five adult patients. A coordinator was nominated for each Australian state and New Zealand, who assisted with survey distribution. Each centre was approached by telephone or email to complete the survey and contacted a month later if they did not respond.

\section{Study design/methods}

After reviewing the existing literature, the group drafted a survey form with the final version established by consensus. The form was tested on HMV therapists at the primary centre to ensure it could be followed easily.

The survey contained six sections as follows. 1) Institutional details: location, type (e.g. tertiary), funding (e.g. government), patient catchment and years of service; 2) criteria for HMV prescription by disease group (e.g. COPD); 3) HMV service details: number of patients receiving HMV, staffing levels, methods of implementation by location/tests utilised/staff involved, methods of follow-up by location/tests utilised/staff involved (0-3 grading from never to always), annual clinic attendances and presence of an outreach service; 4) individual patient data (if available): age, sex, primary indication for HMV (table 1), duration of therapy, adherence to therapy, interface and machine settings (mode, inspiratory positive airway pressure, expiratory positive airway pressure and backup rate); 5) local database: current database for that centre, data collected, what data should be collected, support for creation of a national database and centre willing to participate; and 6) problems encountered with setting up a HMV service (online supplementary material).

\section{Analysis}

Data were examined with descriptive statistics including the Shapiro-Wilk test for normality. Results are expressed as rates, proportions (with $95 \%$ confidence intervals), mean \pm SD (where Shapiro-Wilk $\mathrm{p}>0.05)$ and median with interquartile range (where Shapiro-Wilk $\mathrm{p}<0.05$ ). The minimum prevalence rates for HMV usage (per 100,000 of population) and population density (population/land area) were calculated from survey data combined with national census figures for Australia and New Zealand.

Data were grouped by: country (Australia and New Zealand); centre size ("larger" centres having more patients than the median centre and "smaller" centres having equal or fewer); and centre experience ("older" centres having more years' experience than the median centre and "newer" centres having equal or fewer). Chi-squared analysis (with Yates correction where needed) was used to determine the significance of any differences between the groups, including implementation and follow-up data. Descriptive analyses only are presented for comparisons between Australian states and territories due to the smaller group sizes. Spearman's rank correlation coefficient was used to compare continuous variables, including the relationship between years of experience and patient numbers across centres.

\section{RESULTS}

\section{Response rate and dataset}

34 centres were identified with 28 centres completing the survey (response rate $82 \%$ ). One centre caring for only four patients was excluded from the analysis. The remaining 27 centres (21 Australian and six in New Zealand) cared for 2,725 patients receiving HMV (fig. 1). Data on the general indication for therapy (e.g. obstructive disease) was available for 2,705 (99\%) patients and a specific diagnosis (e.g. COPD) in 2,466 (90\%), on sex and age for $2,302(85 \%)$, on machine type for 2,061 (76\%) and on machine interface/settings for 1,710 (63\%) patients. All centres gave complete responses to qualitative questions on HMV.

\section{Prevalence of HMV usage}

The minimum prevalence of HMV usage in Australia was 9.8 patients per 100,000 population and in New Zealand was 12.0 patients per 100,000 population. Variation in prevalence

\section{TABLE 1 Indications for home mechanical ventilation}

\begin{tabular}{lc} 
Indication & Proportion \% \\
\hline Obstructive pathologies & $13.2(11.9-14.5)$ \\
COPD & $8.0(7.0-9.0)$ \\
Cystic fibrosis & $0.4(0.3-0.8)$ \\
Bronchiolitis obliterans & $0.2(0.1-0.4)$ \\
Other obstructive pathology & $2.0(1.6-2.7)$ \\
Centre unable to subcategorise & $2.5(2.0-3.2)$ \\
Restrictive pathologies & $9.5(8.4-10.7)$ \\
Kyphoscoliosis & $5.6(4.8-6.5)$ \\
Thoracoplasty & $0.6(0.3-0.9)$ \\
Pulmonary fibrosis & $0.5(0.3-0.9)$ \\
Previous TB & $0.4(0.2-0.7)$ \\
Other restrictive pathology & $1.0(0.7-1.5)$ \\
Centre unable to subcategorise & $1.4(1.0-1.9)$ \\
Neuromuscular disease & $30.2(28.5-31.9)$ \\
Motor neurone disease & $8.4(7.4-9.5)$ \\
Polio & $3.2(2.6-4.0)$ \\
Muscular dystrophy & $6.4(5.5-7.4)$ \\
Spinal cord injury & $2.1(1.6-2.7)$ \\
Other neuromuscular disease & $5.6(4.8-6.5)$ \\
Centre unable to subcategorise & $4.3(3.6-5.1)$ \\
Obesity hypoventilation syndrome & $31.0(29.3-32.8)$ \\
Central pathology & $2.9(2.3-3.6)$ \\
Other & $13.2(12.0-14.6)$ \\
&
\end{tabular}

Data are presented as median $(95 \% \mathrm{Cl})$. COPD: chronic obstructive pulmonary disease; TB: tuberculosis 
by region is shown in figure 2 . The prevalence of HMV usage correlated with the absolute population $(\mathrm{r}=0.83 ; \mathrm{p}=0.02)$ and population density of each major region $(r=0.74 ; p=0.05)$, but not with absolute state land area $(\mathrm{r}=-0.26 ; \mathrm{p}=0.54)$.

\section{Patient characteristics and indication for HMV therapy}

The mean $\pm S D$ age of patients receiving HMV varied only slightly between centres, at $57.5 \pm 4.2$ yrs. $58 \%$ of patients were male (95\% CI 56-60\%). The mean duration of HMV therapy was $4.0 \pm 1.7$ yrs. Table 1 presents the proportion of patients treated for each major indication and subcategory. Table 2 and figure 3 compare the prescribing patterns between Australia and New Zealand, larger and smaller centres, and older and newer centres.

\section{Machine settings, interface and adherence}

Most patients used pressure-cycled machines (95.5\%, 95\% CI $94.6-96.3 \%)$, in spontaneous $(42.6 \%, 95 \%$ CI $40.3-45.0 \%)$ or spontaneous-timed $(56.2 \%, 95 \%$ CI $53.8-58.5 \%)$ mode, with a humidifier $(86.9 \%$, 95\% CI $85.1-88.5 \%)$. For pressure-cycled machines, median (interquartile range) settings were inspiratory positive airway pressure $17.5(16.0-19.3) \mathrm{cmH}_{2} \mathrm{O}$, expiratory positive airway pressure $8.9(8.0-9.2) \mathrm{cmH}_{2} \mathrm{O}$, mean back-up rate $15.8( \pm 2.5)$ breaths $\cdot \mathrm{min}^{-1}$. The commonest interface was an oronasal $(62.1 \%, 95 \%$ CI $59.8-64.3 \%)$ or nasal mask $(32.8 \%, 95 \%$ CI $30.7-35.0 \%)$. Mean adherence was $7.3( \pm 1.3) \mathrm{h}$ per day, excluding ventilator-dependent patients who comprised $4.4 \%$ (95\% CI $3.7-5.3 \%)$ of the population. A small proportion of patients was ventilated via a tracheostomy $(3.1 \%, 95 \%$ CI $2.4-$ $4.0 \%)$ or received phrenic nerve stimulation $(0.5 \%, 95 \% \mathrm{CI}$ $0.2-0.9 \%)$. Smaller centres had a lower proportion of ventilatordependent $(1.0 \%$ versus $4.5 \%$; $=0.001)$ or tracheostomised $(0.1 \%$ versus $2.3 \% ; \mathrm{p}=0.02)$ patients compared to larger centres. There was no significant variation in machine settings based on centre location, size or years of experience.

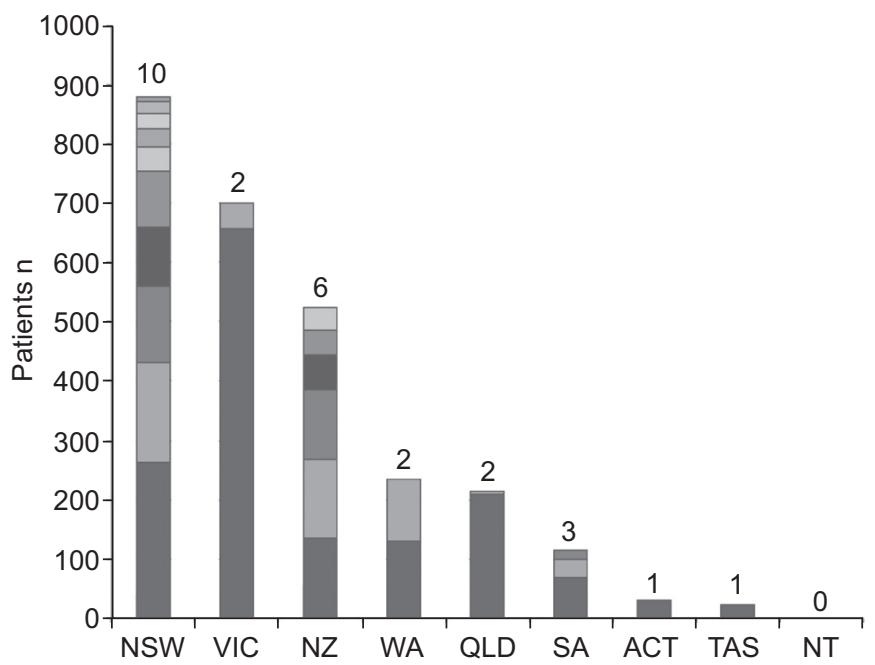

FIGURE 1. Distribution of patients/responding centres. Numbers are cumulative, subdivided by centres. NSW: New South Wales; VIC: Victoria; NZ: New Zealand; WA: Western Australia; QLD: Queensland; SA: South Australia; ACT: Australian Capital Territory; TAS: Tasmania; NT: Northern Territory.

\section{Centre demographics and staffing}

The majority of centres that responded were tertiary (78\%), government-funded (74\%) hospitals. Median centre size was 60 patients (interquartile range 31-130; range 6-658). 13 centres were classified as larger centres and managed 2,311 patients whilst 14 centres were classified as smaller and managed 414 patients. Median centre experience was 13.5 yrs (interquartile range 10.5-18.5; range 2-28). 11 centres were classified as older centres (1,634 patients) whilst 12 centres were classified as newer centres (683 patients). There was no significant relationship between the number of patients cared for by a centre and the number of years that a centre had provided a HMV service $(\mathrm{r}=0.34 ; \mathrm{p}=0.12)$.

Centres across Australia and New Zealand had funded positions for 41 equivalent full-time staff members comprising $36 \%$ nurses, $34 \%$ physicians, $19 \%$ physiotherapists and $11 \%$ scientists. The median staffing per centre was 1.2 full-time equivalent staff members (interquartile range 0.85-7.35). Overall, there were 64 patients per full-time staff member, with considerable variation by centre location (fig. 4). Centres in New Zealand cared for more patients per staff member than Australian centres ( 84 versus 61; $\mathrm{p}=0.01$ ), larger centres cared for more patients per staff member than smaller centres (84 versus 29; $\mathrm{p}<0.001$ ), whilst older centres cared for more patients per staff member than newer centres (83 versus 38; $\mathrm{p}<0.001$ ). An outreach service with home visits/contact was provided by $35 \%$ of centres, caring for a total of 1,375 patients, performing 0.8 visits per patient per year. The commonest reported difficulty with establishing a HMV centre was lack of resources, including funding for staff and equipment.

\section{HMV implementation and follow-up}

Implementation methodology for HMV was generally uniform between centres in Australia and New Zealand, between larger and smaller centres, and between older and newer centres. Centres implemented HMV with medical, nursing, physiotherapy

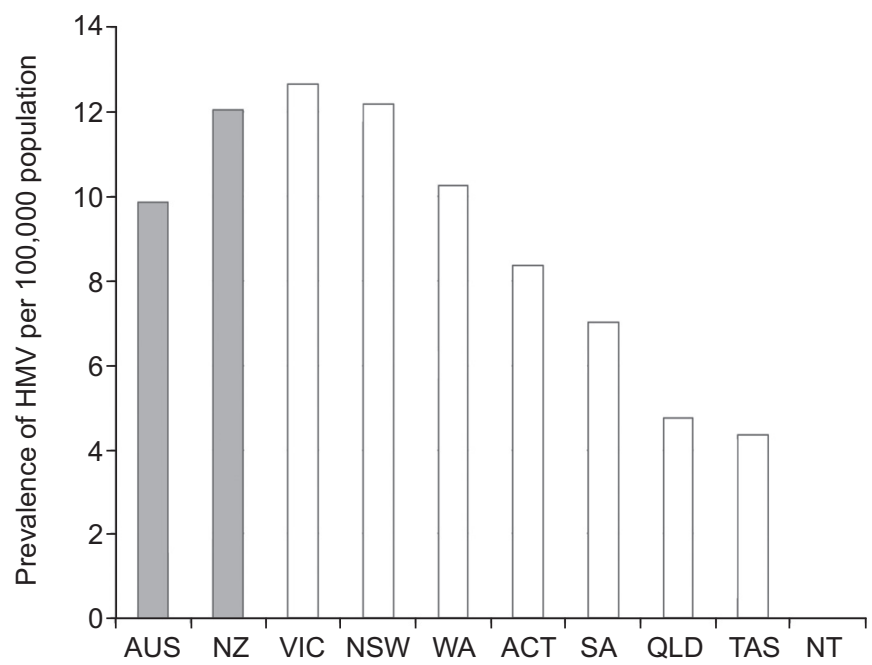

FIGURE 2. Prevalence of home mechanical ventilation (HMV) usage in Australia (AUS), Australian states and New Zealand (NZ). VIC: Victoria; NSW: New South Wales; WA: Western Australia; ACT: Australian Capital Territory; SA: South Australia; QLD: Queensland; TAS: Tasmania; NT: Northern Territory. 


\begin{tabular}{|c|c|c|c|}
\hline TABLE 2 & $\begin{array}{l}\text { Prescribing patte } \\
\text { ventilation accor } \\
\text { experience }\end{array}$ & $\begin{array}{l}\text { of home mecha } \\
\text { to centre locat }\end{array}$ & size and \\
\hline Indication & Australia & New Zealand & $\mathrm{p}$-value \\
\hline COPD & $9.6(8.4-10.9)$ & $1.1(0.5-2.5)$ & $<0.0001$ \\
\hline Restriction & $10.6(9.4-12.0)$ & $5.1(3.6-7.4)$ & 0.0003 \\
\hline NMD & $32.6(30.7-34.6)$ & $20.0(16.8-23.6)$ & $<0.0001$ \\
\hline $\mathrm{OHS}$ & $25.6(23.8-27.4)$ & $53.7(49.4-57.9)$ & $<0.0001$ \\
\hline Indication & Larger centres & Smaller centres & $p$-value \\
\hline COPD & $6.6(5.7-7.7)$ & $15.0(11.9-18.7)$ & $<0.0001$ \\
\hline Restriction & $9.4(8.3-10.7)$ & $9.6(7.2-12.9)$ & 0.67 \\
\hline NMD & $32.7(30.8-34.6)$ & $14.7(11.6-18.5)$ & $<0.0001$ \\
\hline OHS & $28.2(26.4-30.1)$ & $45.2(40.4-50.0)$ & $<0.0001$ \\
\hline Indication & Older centres & Newer centres & $\mathrm{p}$-value \\
\hline COPD & $8.7(7.4-10.2)$ & $7.6(5.9-9.8)$ & 0.21 \\
\hline Restriction & $10.0(8.6-11.5)$ & $8.5(6.6-10.8)$ & 0.25 \\
\hline NMD & $34.0(31.7-36.3)$ & $19.5(16.7-22.6)$ & $<0.0001$ \\
\hline OHS & $24.8(22.7-26.9)$ & $44.2(40.5-48.0)$ & $<0.0001$ \\
\hline
\end{tabular}

and scientific staff involvement, in an in-patient setting, utilising polysomnography (PSG), arterial blood gas analysis (ABG) and transcutaneous carbon dioxide monitoring (table 3). Compared with New Zealand, Australian centres were more likely to use PSG in implementing therapy $(p=0.02)$.

Follow-up methodology was similar when comparing centres by country, size and age. Follow-up was most commonly performed every 6 months by medical staff in a clinic setting, utilising symptom review, ABG and pulse oximetry (table 4). Follow-up was more likely to involve nursing staff in larger centres than smaller centres $(p=0.05)$. There was a trend towards using PSG as a follow-up test in Australian centres more frequently than in centres in New Zealand $(p=0.08)$.

\section{Criteria for HMV prescription}

HMV was prescribed for all diagnostic groups by the majority of centres. However, for COPD, some centres only used HMV as a bridge to transplantation $(n=4)$ or not at all $(n=6)$. Centres used a wide variety of criteria for commencing $\mathrm{HMV}$ across the range of disease groups. For COPD, hypercapnia was a common requisite, but the cut-off level (arterial carbon dioxide tension range 45$55 \mathrm{mmHg}$ ) and timing (daytime versus sleep) varied between centres. For NMD, some centres used specific published evidence/guidelines [22], whilst others required improvements in PSG parameters or awake hypoxia for ongoing HMV. For OHS, some centres implemented HMV as a rescue therapy after continuous positive airway pressure (CPAP) had failed, whereas others implemented HMV as first-line therapy based on body mass index (BMI), awake hypercapnia and symptoms.

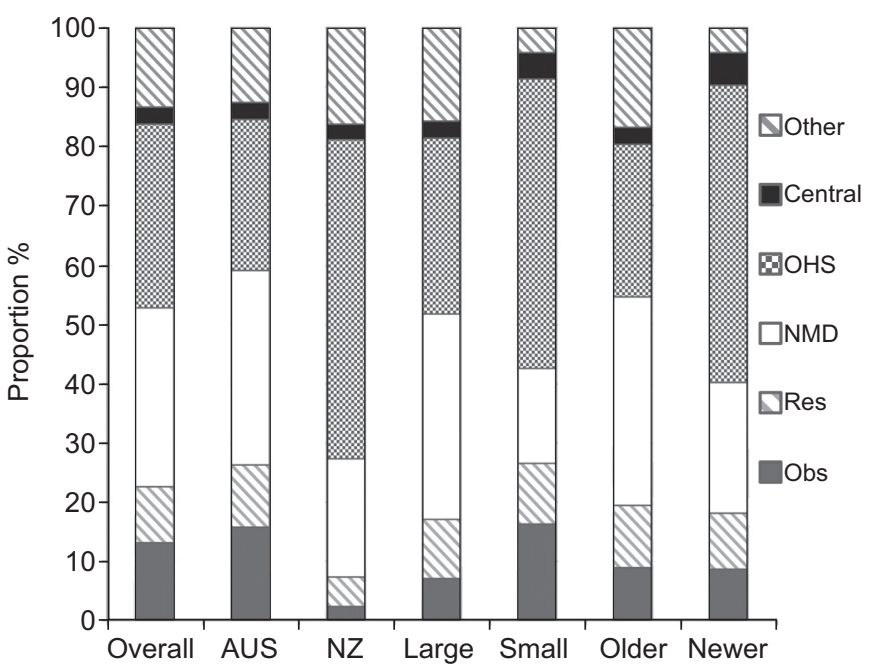

FIGURE 3. Indications for prescription of home mechanical ventilation according to centre location, size and experience. AUS: Australia; NZ: New Zealand; OHS: obesity hypoventilation syndrome; NMD: neuromuscular disease; Res: restrictive disease; Obs: obstructive disease.

\section{DISCUSSION}

This is the first study that comprehensively assesses HMV usage in Australia and New Zealand. Our results highlight key messages on local practice, but indicate trends that are likely to be occurring worldwide.

The prevalence of HMV usage in Australia (9.8 patients per 100,000 population) and New Zealand (12.0 patients per 100,000 population) appears higher than Europe (6.6 patients per 100,000 population) [19] and Hong Kong (2.9 patients per 100,000 population) [20], but significantly lower than Norway (19.9 patients per 100,000 population) [21] or Sweden (20 patients per 100,000 population) [22]. Why do the prevalence rates vary so much between countries? The Hong Kong study [20] excluded institutionalised patients, which would reduce the prevalence in comparison to the current study, which included patients in a chronic care environment. The largest study of European practice was conducted $10 \mathrm{yrs}$ ago making direct comparison difficult [19]. The current study also estimates minimum prevalence, as $18 \%$ of identified centres did not respond. The actual prevalence is certain to be higher, although the state coordinators reported that the non-responding centres were small. Many of the previously reported prevalence rates are likely to represent a moving target. Both Hong Kong and Sweden have demonstrated rapid increases in HMV usage with a doubling over a 5-6-yr period [20, 22]; similar changes are likely to have occurred across Europe where prevalence is almost certain to have increased. HMV usage will also vary according to local prescribing practices and availability of resources. Norway and Sweden have established national data registries to track prevalence rates. Health funders are beginning to demand more up-to-date information. Our survey respondents almost unanimously supported the creation of a national database and indicated their willingness to participate. The authors are currently in the process of establishing a national data registry for Australia and New Zealand. 


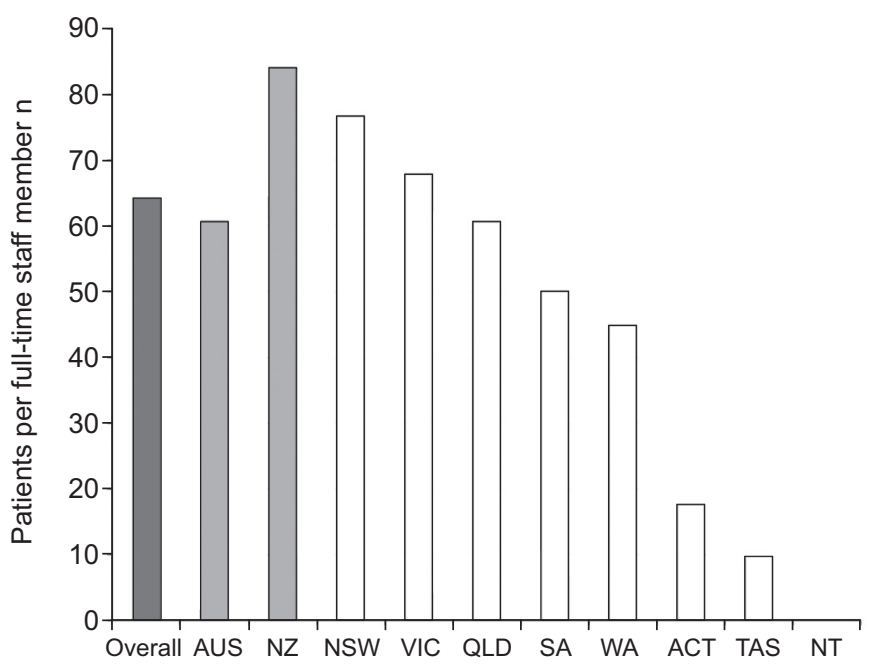

FIGURE 4. Number of patients cared for per full-time staff member. AUS Australia; NZ: New Zealand; NSW: New South Wales; VIC: Victoria; QLD: Queensland; SA: South Australia; WA: Western Australia; ACT: Australian Capital Territory; TAS: Tasmania; NT: Northern Territory.

Although comparison between countries is difficult, several findings locally contrast sharply with previous studies. COPD $(8.0 \%)$ is an uncommon indication in this study, with higher proportions of COPD prescriptions in Europe and Hong Kong $(34-49 \%)[19,20]$. Reasons for this difference are varied. First, our study finds some limitation in access to HMV for COPD, with several centres, particularly in New Zealand, being unable to obtain government funded ventilators for this indication. Secondly, there may be lower demand for HMV locally: Australia and New Zealand have younger populations [25] and lower smoking rates [26] than most European countries, and we can speculate therefore that fewer individuals require treatment, although no comparative studies exist to confirm this. Thirdly, there may be a higher threshold for treatment than elsewhere; although national guidelines for prescription are still under development, responses from centres and the authors' own practice suggest that various criteria need to be met before HMV can be prescribed in COPD, including maximal medical therapy, treatment of all reversible/modifiable factors, two or more hospital admissions for hypercapnic respiratory failure, PSG demonstration of nocturnal hypoventilation, toleration of $\geqslant 1$ month's trial HMV and demonstrable physiological improvement with treatment. These criteria may have evolved in response to cautious application of the previous paradigm of low-pressure HMV in COPD, given conflicting evidence regarding its benefits [2730], including a recent Australian study, which demonstrated a small survival benefit but worsened quality of life [17]. More recently, studies suggest that a different approach to HMV in COPD using higher pressures may be more successful [18]; however, the lead time for new practices to become widespread nationally mean that any such changes are not rapidly reflected in surveys such as this, and emphasise the potential value of prospective registers.

The low proportion of patients treated for COPD may reflect more rapid growth in demand from other groups, especially OHS $(31.0 \%)$ our commonest indication, contrasting with

\begin{tabular}{|c|c|c|c|c|c|c|}
\hline \multirow[t]{2}{*}{ TABLE 3} & \multicolumn{6}{|c|}{$\begin{array}{l}\text { Implementation practice: centres who } \\
\text { responded frequently/always }\end{array}$} \\
\hline & In-patient & Medical & Nursing & ABG & PSG & $\mathrm{Ptc}, \mathrm{CO}_{2}$ \\
\hline Overall & 65 & 42 & 58 & 96 & 77 & 62 \\
\hline Australia & 60 & 50 & 55 & 100 & 90 & 70 \\
\hline New Zealand & 83 & 17 & 67 & 83 & 33 & 33 \\
\hline Larger & 75 & 50 & 58 & 100 & 75 & 67 \\
\hline Smaller & 57 & 36 & 57 & 93 & 79 & 57 \\
\hline Older & 56 & 56 & 67 & 100 & 78 & 67 \\
\hline Newer & 75 & 33 & 58 & 92 & 75 & 58 \\
\hline
\end{tabular}

previous studies with much lower rates (e.g. 4.4\% in Hong Kong [20]). Given the obesity epidemic, it is perhaps not unexpected that OHS is now the commonest indication for HMV. The prevalence rates for obesity $\left(\mathrm{BMI}>30 \mathrm{~kg} \cdot \mathrm{m}^{-2}\right.$ ) have risen rapidly to $20 \%$ and $26 \%$ in Australia and New Zealand, respectively [31, 32]. The evidence for HMV in OHS is steadily increasing but remains far from comprehensive. Longer term observational studies of HMV have demonstrated physiological improvement, decreased hospitalisations and improved quality of life but randomised controlled trials assessing survival are needed $[11,33]$. CPAP may be equally effective in subgroups with less severe nocturnal hypoxaemia [9]. Is the clinical usage of HMV for OHS outpacing the available evidence? Several centres in the current study reported routine use HMV as first-line therapy for OHS instead of CPAP. However, OHS also appears to be growing in significance in Europe with Norwegian centres $(22 \%)$ and a single Swiss centre $(36 \%)$ reporting higher rates of HMV prescription for this indication $[21,25]$.

The proportion of patients on HMV for NMD is similar between Europe (35\%) and the current study. The role of HMV in NMD, particularly motor neurone disease, is well established. HMV improves survival and quality of life in patients with significant muscle weakness, or symptomatic hypercapnia, combined with intact bulbar function [6]. Prevalence rates for NMD are likely to be stable. Higher levels of evidence and availability of

\begin{tabular}{|c|c|c|c|c|c|c|}
\hline TABLE 4 & $\begin{array}{l}\text { Follow-L } \\
\text { frequen }\end{array}$ & $\begin{array}{l}\text { p prac } \\
\text { y/alwa }\end{array}$ & $\begin{array}{l}\text { ce: cent } \\
\text { s }\end{array}$ & res resp & nding & \\
\hline & Clinic & Home & Medical & Nursing & PSG & Oximetry \\
\hline Overall & 100 & 8 & 96 & 50 & 38 & 54 \\
\hline Australia & 100 & 10 & 100 & 45 & 50 & 45 \\
\hline New Zealand & 100 & 0 & 83 & 67 & 0 & 83 \\
\hline Large & 100 & 17 & 100 & 75 & 33 & 58 \\
\hline Small & 100 & 0 & 93 & 36 & 43 & 50 \\
\hline Older & 100 & 11 & 100 & 56 & 44 & 22 \\
\hline Newer & 100 & 0 & 92 & 50 & 25 & 67 \\
\hline
\end{tabular}


international guidelines [34] may contribute to the consistency of practice observed between Europe, Australia and New Zealand. Several centres in the current study used published data to direct HMV prescription for motor neurone disease. Despite a similar proportion of patients with NMD, we note that our study rate of $3 \%$ for tracheostomy is lower than the overall rate found in Europe; it is however consistent with several (predominantly Northern European) countries surveyed within the Eurovent study [19].

Overall, there is a need for guidelines to allow consistent practice across disease groups, particularly OHS and COPD. Quality control of HMV equipment and practice needs to be monitored as considerable variation can exist between centres [35]. Indeed surveying authors centres with the same question set reveals little progress has been made in standardising quality control methodology, or defining best practice (see online supplementary material). This less comprehensive survey implies that clinicians generally pay close regard to patient and machine issues during clinic visits, but that various strategies for overall machine maintenance exist including in-house, third party and manufacturer based servicing. Manufacturers now specify long servicing intervals which imply impressive reliability, but even perfect equipment performance cannot guarantee adequate treatment delivery without structured review of the interaction between patients and their ventilators.

Further research is needed to demonstrate the longer-term benefits of HMV in OHS. Health administrators need to be aware that OHS is likely to be the foremost indication for HMV in the foreseeable future, that treatment is likely to be prolonged over many years [10] and resources need to be planned accordingly.

Another key finding is that HMV prescribing patterns and staffing levels differ depending on centre location, size and experience. This is consistent with data from the Eurovent study [19], which found significant variations in practice according to centre location and experience. The current study found that the more densely populated Australian states had the highest prevalence of HMV usage. Marked regional differences were noted in Eurovent [19] and similar studies in Norway and Sweden [22, 23] with rates as high as 31 patients per 100,000 population. One possible interpretation of these findings is that rural patients may find it more difficult to access therapy due to the concentration of specialised HMV centres in larger cities. In Australia, patients with chronic health conditions who reside in rural areas may find it more difficult to access healthcare and this may result in worse outcomes [36, 37].

Centres in New Zealand and smaller, newer centres are more likely to manage patients with OHS, whilst Australian centres and larger, more experienced centres are more likely to manage patients with NMD. The higher prevalence of obesity in New Zealand could contribute to the greater proportion of OHS patients treated. The propensity for larger, more experienced centres to manage NMD may reflect the complexity of these patients, which requires an experienced, multidisciplinary team. In keeping with this, European data indicate that smaller centres manage fewer NMD patients [19]. Australian centres are more likely to order sleep studies when implementing and following-up HMV therapy. Anecdotally, the waiting times for in-laboratory sleep studies in many New Zealand laboratories exceeds 12 months, which may be limiting access to sleep studies relative to Australia. More patients per staff member are observed in New Zealand and larger, more experienced centres. These centres may have developed processes that can deal with larger patient numbers efficiently, whilst centres in New Zealand may be relatively less staffed compared to Australian centres. However, such speculation about variations according to centre size, location and experience require further research to determine the reasons that underlie these differences.

Limitations of the study include the cross-sectional design, which can detect associations between factors but not determine causation. Surveys are subject to recall bias; however, individual patient data were collected in the form of a database by many centres, which minimises such bias. Misclassification of complicated obstructive sleep apnoea as OHS could contribute to the high prevalence rate for HMV usage in OHS. Smaller centres and privately funded patients are unlikely to be detected by this survey but these numbers are likely to be small given the complexity of ongoing follow-up and the cost of the equipment. Patient crossover between centres is possible, but less likely given the large distances between centres and the fact that some states, such as Victoria, have a centralised model of care. Many of these limitations can be overcome by collecting individual data longitudinally in a national data registry. Treatment outcomes could also be assessed in this way. Almost all centres that participated supported the establishment of a data registry and indicated their willingness to participate.

In conclusion, this study has demonstrated considerable variability in the prevalence and pattern of domiciliary HMV usage in Australia and New Zealand. OHS is the commonest indication, which differs from the most comprehensive survey in Europe and may reflect changing patterns of HMV prescription globally. Practice varies according to centre location, size and experience. The lack of consensus with prescribing practices highlights the need for national HMV guidelines and ongoing research into the effects of treatment. Establishment of a national data registry would allow longitudinal analysis of the trends in HMV usage and contribute to the understanding of treatment outcomes. There appears to be widespread support for such an initiative.

\section{SUPPORT STATEMENT}

ResMed Foundation provided an unconditional grant for investigator initiated research.

\section{STATEMENT OF INTEREST}

Statements of interest for D.J. Garner, D.J. Berlowitz, M. Howard, N. McArdle, M.T. Naughton, A. Piper and A. Young and the study itself can be found at www.erj.ersjournals.com/site/misc/statements.xhtml

\section{ACKNOWLEDGEMENTS}

Author affiliations are as follows. D.J. Garner: The Alfred Hospital, Prahran, Melbourne, Australia; D.J. Berlowitz: Institute for Breathing and Sleep, Austin Health, Heidelberg, and The University of Melbourne, Melbourne, Australia; J. Douglas: The Prince Charles Hospital, Brisbane, Australia; N. Harkness: The Royal Hobart Hospital, Hobart, Australia; M. Howard: Institute for Breathing and Sleep, Austin Health, Heidelberg, and The University of Melbourne, Melbourne, Australia; N. McArdle: West Australian Sleep Disorders Research Institute, Dept of Pulmonary Physiology and Sleep Medicine, Sir Charles Gairdner Hospital, Perth, and University of Western 
Australia, School of Medicine and Pharmacology, Nedlands, Australia; M.T. Naughton: The Alfred Hospital, Prahran, and Monash University, Melbourne, Australia; A. Neill: University of Otago, and Wellington Hospital, Wellington, New Zealand; A. Piper: Royal Prince Alfred Hospital, Camperdown, Australia; A. Yeo: Community Respiratory Service, Royal Adelaide Hospital, Adelaide, Australia; A. Young: Royal Prince Alfred Hospital, Camperdown, and Box Hill Hospital, Box Hill, Australia.

The authors acknowledge all respondents from participating home mechanical ventilation centres.

\section{REFERENCES}

1 Dellborg C, Olofson J, Midgren B, et al. Impact of home mechanical ventilation on health-related quality of life in patients with chronic alveolar hypoventilation: a prospective study. Clin Respir J 2008; 2: 26-35.

2 Lewarski JS, Gay PC. Current issues in home mechanical ventilation. Chest 2007; 132: 671-676.

3 Windisch W. Impact of home mechanical ventilation on healthrelated quality of life. Eur Respir J 2008; 32: 1328-1336.

4 Bourke SC, Tomlinson M, Williams TL, et al. Effects of noninvasive ventilation on survival and quality of life in patients with amyotrophic lateral sclerosis: a randomised controlled trial. Lancet Neurol 2006; 5: 140-147.

5 Berlowitz DJ, Detering K, Schachter L. A retrospective analysis of sleep quality and survival with ventilatory support in motor neuron disease. Amyotroph Lateral Scler 2006; 7: 100-106.

6 Farrero E, Prats E, Povedano M, et al. Survival in amyotrophic lateral sclerosis with home mechanical ventilation: the impact of systematic respiratory assessment and bulbar involvement. Chest 2005; 127: 2132-2138.

7 Domenech-Clar R, Nauffal-Manzur D, Perpina-Tordera M, et al. Home mechanical ventilation for restrictive thoracic diseases: effects on patient quality-of-life and hospitalizations. Respir Med 2003; 97: 1320-1327.

8 Gustafson T, Franklin KA, Midgren B, et al. Survival of patients with kyphoscoliosis receiving mechanical ventilation or oxygen at home. Chest 2006; 130: 1828-1833.

9 Piper AJ, Wang D, Yee BJ, et al. Randomised trial of CPAP vs bilevel support in the treatment of obesity hypoventilation syndrome without severe nocturnal desaturation. Thorax 2008; 63: 395-401.

10 Budweiser S, Riedl SG, Jorres RA, et al. Mortality and prognostic factors in patients with obesity-hypoventilation syndrome undergoing noninvasive ventilation. J Intern Med 2007; 261: 375-383.

11 Priou P, Hamel JF, Person C, et al. Long-term outcome of noninvasive positive pressure ventilation for obesity hypoventilation syndrome. Chest 2010; 138: 84-90.

12 Young AC, Wilson JW, Kotsimbos TC, et al. Randomised placebo controlled trial of non-invasive ventilation for hypercapnia in cystic fibrosis. Thorax 2008; 63: 72-77.

13 Wedzicha JA, Muir JF. Noninvasive ventilation in chronic obstructive pulmonary disease, bronchiectasis and cystic fibrosis. Eur Respir J 2002; 20: 777-784.

14 Anton A, Guell R. Home mechanical ventilation in COPD: do we know when and how to use it? Chest 2000; 118: 1525-1526.

15 Elliott MW. Non-invasive ventilation in stable COPD? Thorax 2009; 64: 553-556.

16 Tuggey JM, Plant PK, Elliott MW. Non-invasive ventilation for recurrent acidotic exacerbations of COPD: an economic analysis. Thorax 2003; 58: 867-871.

17 McEvoy RD, Pierce RJ, Hillman D, et al. Nocturnal non-invasive nasal ventilation in stable hypercapnic COPD: a randomised controlled trial. Thorax 2009; 64: 561-566.
18 Dreher M, Storre JH, Schmoor C, et al. High-intensity versus lowintensity non-invasive ventilation in patients with stable hypercapnic COPD: a randomised crossover trial. Thorax 2010; 65: 303-308.

19 Lloyd-Owen SJ, Donaldson GC, Ambrosino N, et al. Patterns of home mechanical ventilation use in Europe: results from the Eurovent survey. Eur Respir J 2005; 25: 1025-1031.

$20 \mathrm{Chu} \mathrm{CM}, \mathrm{Yu}$ WC, Tam CM, et al. Home mechanical ventilation in Hong Kong. Eur Respir J 2004; 23: 136-141.

21 Tollefsen E, Gulsvik A, Bakke P, et al. Prevalens av hjemmerespiratorbehandling i Norge [Prevalence of home ventilation therapy in Norway]. Tidsskr Nor Laegeforen 2009; 129: 2094-2097.

22 Laub M, Berg S, Midgren B. Home mechanical ventilation in Sweden - inequalities within a homogenous health care system. Respir Med 2004; 98: 38-42.

23 Newton-John HF. Long-term mechanical ventilation of patients in Australia. Med J Aust 1989; 150: 3-6.

24 Chang AY, Marsh S, Smith N, et al. Long-term community noninvasive ventilation. Intern Med J 2010; 40: 764-771.

25 Central Intelligence Agency. CIA World Factbook. www.cia.gov/ library/publications/the-world-factbook/index.html Date last accessed: April 24, 2012.

26 World Health Organization. WHO Report on the Global Tobacco Epidemic. www.who.int/tobacco/global_report/2011/en Date last accessed: April 24, 2012.

27 Pasquina P, Bourqui P, Farr P, et al. Prise en charge et suivi de patients sous ventilation à domicile: l'expérience genevoise [Follow-up of patients with home mechanical ventilation: experience in Geneva, Switzerland]. Rev Med Suisse 2008; 4: 2518-2520.

28 Jones SE, Packham S, Hebden M, et al. Nocturnal intermittent positive pressure ventilation in patients with respiratory failure due to severe COPD: long-term follow up and effect on survival. Thorax 1998; 53: 495-498.

29 Casanova C, Celli BR, Tost L, et al. Long-term controlled trial of nocturnal nasal positive pressure ventilation in patients with severe COPD. Chest 2000; 118: 1582-1590.

30 Clini E, Sturani C, Rossi A, et al. The Italian multicentre study on noninvasive ventilation in chronic obstructive pulmonary disease patients. Eur Respir J 2002; 20: 529-538.

31 New Zealand Ministry of Health, New Zealand Health Survey statistics section on body size. www.health.govt.nz/system/files/ documents/publications/portrait-of-health-june08.pdf. Date last accessed: October 31, 2012. Date last updated: June 6, 2012.

32 Australian Bureau of Statistics 4364.0 - National Health Survey: Summary of Results, 2007-2008 (Reissue). www.abs.gov.au/ ausstats/abs@.nsf/mf/4364.0/ Date last accessed: April 24, 2012. Date last updated: November 24, 2010.

33 Piper AJ, Grunstein RR. Obesity hypoventilation syndrome: mechanisms and management. Am J Respir Crit Care Med 2011; 183: 292-298.

34 Miller RG, Jackson CE, Kasarskis EJ, et al. Practice parameter update: the care of the patient with amyotrophic lateral sclerosis: drug, nutritional, and respiratory therapies (an evidence-based review): report of the Quality Standards Subcommittee of the American Academy of Neurology. Neurology 2009; 73: 1218-1226.

35 Farre R, Lloyd-Owen SJ, Ambrosino N, et al. Quality control of equipment in home mechanical ventilation: a European survey. Eur Respir J 2005; 26: 86-94.

36 Phillips A. Health status differentials across rural and remote Australia. Aust J Rural Health 2009; 17: 2-9.

37 Walker C. Chronic illness and consumer inequality: the impact of health costs on people with chronic illnesses in rural and regional Australia. Aust Health Rev 2007; 31: 203-210. 